\title{
Haematological changes in Trypanosoma evansi infected cattle
}

\author{
S. Sivajothi ${ }^{1}$, B.Sudhakara Reddy ${ }^{2}$, K.Nalini Kumari ${ }^{3}$, V.C.Rayulu ${ }^{4}$ \\ ${ }^{1}$ Assistant Professor, Dept. of Veterinary Parasitology, C.V.Sc., S.V.V.U., Proddatur \\ ${ }^{2}$ Assistant Professor (Veterinary Medicine), TVCC, C.V.Sc., S.V.V.U., Proddatur \\ ${ }^{3}$ Professor and University Head, Dept. of Veterinary Medicine, C.V.Sc., S.V.V.U., Tirupati \\ ${ }^{4}$ Professor and University Head, Dept. of Veterinary Parasitology, C.V.Sc., S.V.V.U., Proddatur \\ *Corresponding author E-mail: sivajothi579@gmail.com
}

Copyright $\odot 2014$ S. Sivajothi et al. This is an open access article distributed under the Creative Commons Attribution License, which permits unrestricted use, distribution, and reproduction in any medium, provided the original work is properly cited.

\begin{abstract}
During the three years period of study twelve cross bred cattle were identified that they were suffering with clinical Trypanosomiasis. Up on clinical examination cattle had anorexia, fever, ocular discharges, dullness and enlarged lymph nodes. Stained peripheral blood examination revealed the presence of Trypanosoma evansi. Haematological abnormalities include decreased TEC, PCV, $\mathrm{Hb}$ and TLC values $(\mathrm{P}<0.01)$. The present leucopaenia was characterized by neutrophilia, eosinophilia and lymphocytopaenia $(\mathrm{P}>0.05)$.
\end{abstract}

Keywords: Anaemia - Cattle - Haematology - Leucopaenia - T. evansi

\section{Introduction}

Trypanosomiasis is a protozoan disease of livestock commonly called as Surra caused by Trypanosoma evansi. The disease is transmitted by Tabanid flies. It affects most of the livestock and wild animals. It is distributed throughout the India and found as endemic. The disease is seen as an outbreak in pre monsoon and in monsoon seasons due to active breeding of the Tabanid flies. The disease is characterized by anaemia, nervous complications, emaciation and death. It causes severe loss to the farmers by the way of poor milk production, reduced ability to work and high mortality. The disease also interferes with immunity and causes immunosuppression of bacterial and viral infections and sometimes also causes vaccination failure. The incidence and the severity of the disease vary with the strain of the parasite as well as the species of host affected [1]. Clinical signs may vary based on the severity of the infection. Prevalence of T.evansi was recorded in different species of animals by different diagnostic methods in India [2, 3]. Haematological and biochemical abnormalities were also recorded in experimental animal infection with T.evansi [4]. Little is known about the haematological changes associated with the local strain of T.evansi in cattle in Andhra Pradesh. Present study was conducted to study the haematological changes in cattle affected with natural infection with T.evansi.

\section{Materials and methods}

Present study was carried out on the cross bred cattle presented to the College Hospital of College of Veterinary Science, Tirupati during the three years period i.e. from 2009 to 2012. Cattle with inappetance, dullness, pyrexia, bilateral ocular discharges, chronic emaciation, and enlarged lymph nodes were screened for the presence of haemoprotozoans. Initially all the cattle were tested for the presence of haemoprotozoans by peripheral wet blood film examination, followed by stained blood smears examination for confirmation of trypanosomes species [5]. Whole blood was collected from the suspected cattle and ten cross bred cattle (control group) in the age group of 4 to 8 years from the dairy farm in College was served as control group. Blood was collected in 10\% EDTA coated vials was used for estimation of packed cell volume (PCV), total leucocyte count (TLC), total erythrocyte count (TEC) and haemoglobin $(\mathrm{Hb})$. The peripheral blood smears were stained by Leishman's stain to study the differential count (DLC) by battlement method following which; the absolute counts were also calculated. Statistical analysis was done by Student's t-test to 
compare between infected and control cattle were obtained; $P$ value of 0.05 or lower was considered to be significant [6].

\section{Results and discussion}

Based on the laboratory examination, twelve cross bred cattle diagnosed that they have T.evansi. Wet blood film examination revealed the presence of motile Trypanosoma organisms in between the RBCs of collected blood from the suspected animals. Up on stained peripheral blood smear examination; organisms were confirmed as T.evansi based on morphology (Figure-1).

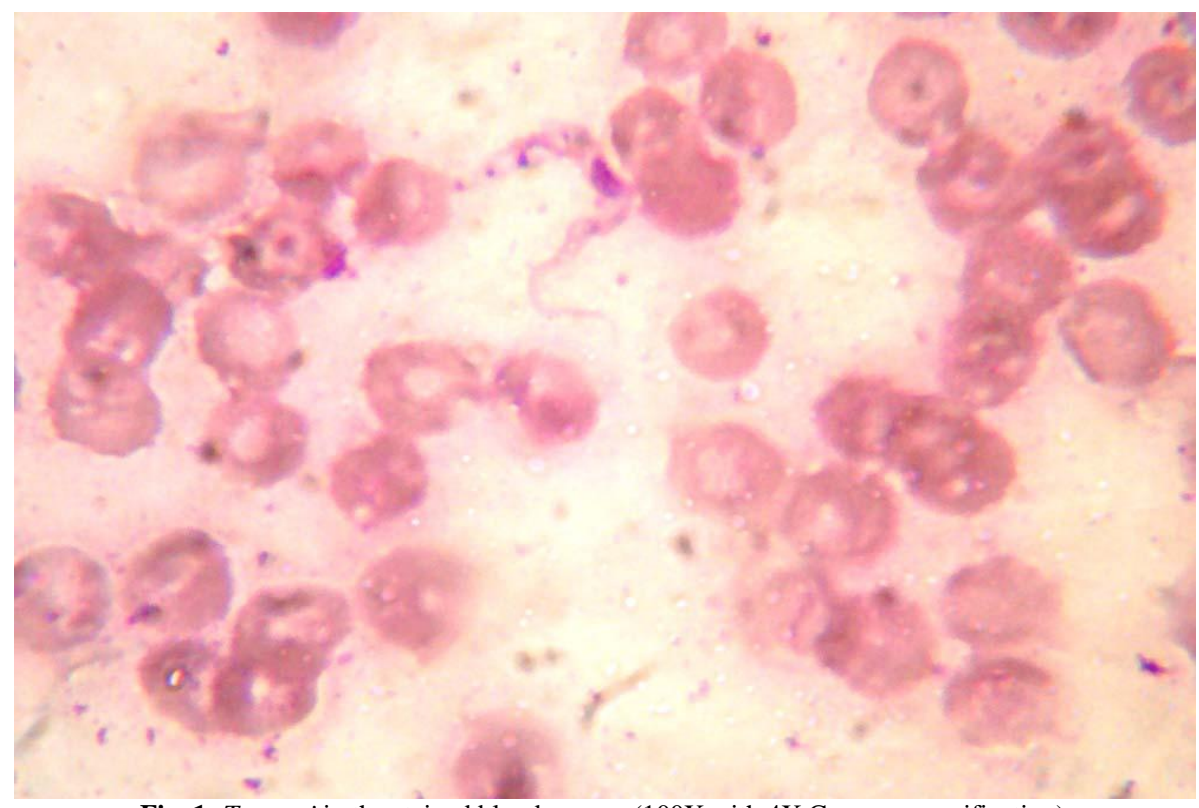

Fig. 1: T.evansi in the stained blood smears (100X with $4 \mathrm{X}$ Camera magnification)

All the cattle exhibited high rise of intermittent temperature $\left(103.2^{0} \mathrm{~F}\right.$ to $\left.105.2^{0} \mathrm{~F}\right)$, dullness, enlarged lymph nodes, conjunctivitis, corneal opacity, anorexia, sunken eye balls, congested conjunctival mucus membranes, bilateral lacrimation, labored breathing, sudden drop of milk yield and emaciation (Figure-2).

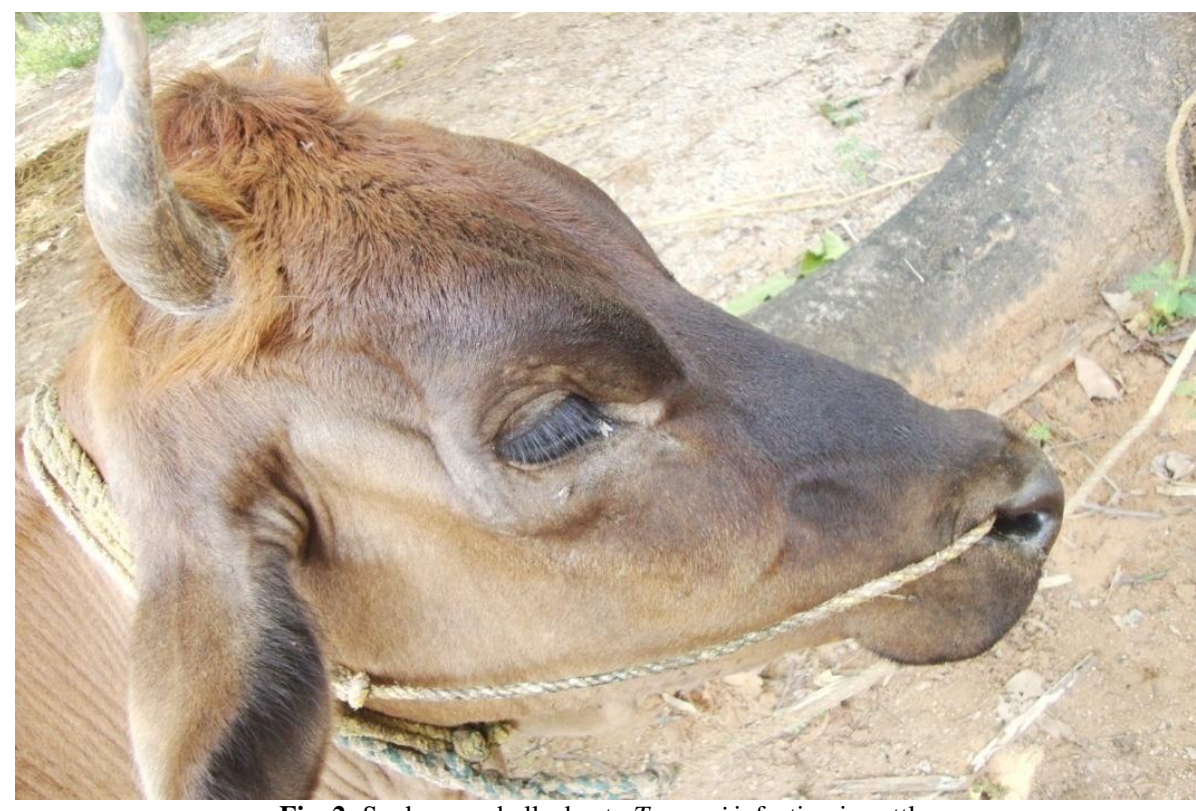

Fig. 2: Sunken eye balls due to T.evansi infection in cattle

In four cattle nervous symptoms like walking in circles, beating the head on walls was also noticed. Mean haematological values in T. evansi infected cattle as well as control cattle were given in Table-1. 
Table 1: Mean haematological values of control and Trypanosoma infected cattle (Mean \pm S.E)

\begin{tabular}{lllll}
\hline Parameters & Control group $(\mathrm{n}=12)$ & Trypanosoma infected cattle $(\mathrm{n}=12)$ & $\mathrm{t}-$ test & $\mathrm{P}$ \\
\hline $\mathrm{Hb}(\mathrm{g} / \mathrm{dl})$ & $10.81 \pm 0.49$ & $8.37 \pm 0.31$ & $4.52^{* *}$ & 0.0007 \\
$\mathrm{PCV}(\%)$ & $31.71 \pm 0.89$ & $28.71 \pm 5.7$ & $2.45^{*}$ & 0.0305 \\
$\mathrm{TEC} \times 10 \%$ cumm & $5.70 \pm 0.20$ & $4.76 \pm 0.80$ & $4.22^{* *}$ & 0.0012 \\
TLC /cumm & $8000.0 \pm 310.9$ & $7328.57 \pm 71.8$ & $1.86^{\mathrm{NS}}$ & 0.0871 \\
Lymphocytes /cumm & $5454.57 \pm 160.4$ & $4828.57 \pm 312.2$ & $1.78^{\mathrm{NS}}$ & 0.0998 \\
Neutrophils /cumm & $2071.86 \pm 112.7$ & $2310.29 \pm 119.8$ & $1.45^{\mathrm{NS}}$ & 0.1728 \\
Eosinophils /cumm & $259.57 \pm 15.67$ & $325.86 \pm 63.5$ & $1.01^{\mathrm{NS}}$ & 0.3314 \\
Monocytes /cumm & $388.43 \pm 11.99$ & $399.29 \pm 28.48$ & $0.35^{\mathrm{NS}}$ & 0.7315 \\
\hline
\end{tabular}

NS - Non Significant $(\mathrm{P}>0.05)$

* Significant $(\mathrm{P}<0.05)$

$* *$ Highly Significant $(\mathrm{P}<0.01)$

The mean TEC, PCV and $\mathrm{Hb}$ reduced significantly $(\mathrm{P}<0.01)$ compared to control group, indicating anemia. The patho physiology of anaemia in Trypanosomiasis is complex and multi factorial in origin [7]. It initiates a cascade of events leading to haemolytic anaemia and cardiovascular collapse [8]. Anaemia caused by mechanical injury to erythrocyte occurs by the lashing action of the powerful locomotory flagella and microtubule reinforced bodies of the millions of the organisms during parasitaemia [9]. Erythrocyte membrane damage has also been associated with adhesion of erythrocytes, platelets and reticulocytes to trypanosome surfaces via sialic acid receptors leading to damages to erythrocyte cell membranes [10]. Trypanosomiasis may cause a drop in feed intake hence there is energy deficit and loss of tissue associated with catabolism of body fat, deficiencies of vitamin C, B and essential amino acids [11]. Inadequate energy supply to erythrocytes may alter the erythrocyte membrane surface therefore leading to weakening of the cell membrane, increased osmotic fragility and haemolysis [12]. Igbokwe and Nwosu explained that anaemia due to massive erythrophagocytosis by an expanded and active mononuclear phagocytic system (MPS) of the host [13]. Low PCV observed in the infected group may be as a result of acute haemolysis due to growing infection. Previous studies have shown that infection with trypanosomes resulted in increased susceptibility of red blood cell membrane to oxidative damage probably as a result of depletion of reduced glutathione on the surface of the red blood cell [14]. Severity of anaemia usually reflects the intensity and duration of parasitaemia.

Reduction in the mean total leucocytes count and mean lymphocyte count was noticed but, it was statistically not significant from the control group $(\mathrm{P}>0.05)$. Increased in the mean neutrophil count, monocyte count and eosinophils count of the infected animals which were statistically not significant from the control groups $(\mathrm{P}>0.05)$. The reduction in leukocyte levels could be a result of immuno-suppression. Abd El-Baky and Salem observed significant leucocytosis, neutrophilia, monocytosis and eosinophilia in naturally infected camels with Trypanosomiasis [15]. The eosinophilia observed is a feature of parasitic infections and is associated with immediate-type hypersensitivity reactions. Significant decrease $(\mathrm{P}<0.05)$ in RBC, Hb, PCV and lymphocyte count was observed by Chaudhary and Iqbal. They also recorded significant $(\mathrm{P}<0.05)$ increase in $\mathrm{WBC}$ and neutrophils in natural Trypanosomiasis in racing dromedary camels in their studies [16]. Leucopaenia in animal Trypanosomiasis has been reported to be due largely to ineffective or depressed granulopoiesis in the bone marrow [17]. The lower counts of WBC, lymphocytes observed in the infected group may be attributed to the immunosuppressive actions of Trypanosome infection [18, 19]. Sulaiman and Adeyemi, reported lymphocytosis in their studies which may be due to generalized lymphoid tissue hyperplasia, characteristic of the acute phase of the disease, during which period, lymph nodes and spleen are remarkably reactive while in chronic infection, the immune system becomes depleted of lymphoid cells [20].

\section{Acknowledgements}

The authors acknowledge the authorities of Sri Venkateswara Veterinary University, Tirupati for providing facilities to carry out this research.

\section{References}

[1] S.Sivajothi, V.C.Rayulu, K.Sujatha, B.S.Reddy, Study of Histopathological Changes in Experimental Trypanosoma evansi Infected Rats. Proc Zool Soc, 2014a DOI 10.1007/s12595-014-0104-9.

[2] S.Sivajothi, V.C. Rayulu, B.S. Reddy, Development of Slide Enzyme Linked Immunosorbent Assay (SELISA) for Detection of Trypanosoma evansi Infection in Bovines. Journal of Advanced Veterinary Research Volume 2 (2012) 15-17.

[3] S.Sivajothi, V.C.Rayulu, P. Malakondaiah, D. Sreenivasulu, Diagnosis of Trypanosoma evansi in bovines by indirect ELISA. J Parasit Dis. 2014b, DOI 10.1007/s12639-014-0465-z.

[4] S.Sivajothi, V.C.Rayulu, B.S.Reddy, Haematological and biochemical changes in experimental Trypanosoma evansi infection in rabbits. Journal of parasitic diseases, 2013a, DOI 10.1007/s12639-013-0321-6.

[5] S.Sivajothi, V.C.Rayulu, P.Malakondaiah, D.Sreenivasulu, Colloidal Dye Immunobinding Assay for Detection of Trypanosoma evansi Antibodies in Animals, International Journal of Livestock Research. 2013b, Vol 3(3), 48-56.

[6] B.S.Reddy, K.N.Kumari, S.Sivajothi, Haemato-biochemical findings and thyroxin levels in canine demodicosis. Comp Clin Pathol. 2014, DOI 10.1007/s00580-014-1893-y. 
[7] J.Naessens, H. Kitani, Y. Yagi, K.Sekikawa, F.Iraqqi, TNF-a mediates the development of anaemia in a murine Trypanosoma brucei rhodesiense infection, but not the anaemia associated with a murine T. congolense infection, Clinical and Experimental Immunology 139(3): (March 2005), 403-410, PMID: PMC 1809320.

[8] V.O.Anosa, Haematology and biochemical changes in human and animal trypanosomiasis. Part II. Rev Elev Med Vet Pays Trop, 1988, 41: $151-164$.

[9] K.Vickerman, L. Tetley, Biology and ultra-structure of trypanosomes in relation to pathogenesis. In: Pathogenecity of trypanosomes , Proceedings of a workshop, pp. 231- 31, ISBN 0- 88936-214-9, Nairobi, Kenya, November 20-23, 1978.

[10] S.A.Shehu, N.D.G. Ibrahim, K.A.N.Esievo, G.Mohammed, Role of erythrocyte surface sialic acid inducing anaemia in Savannah Brown bucks experimentally infected with Trypanosoma evansi, Veterenarski Arhiv 26(6): (October 2006), 521-530, ISSN 0372-5480.

[11] I.O. Igbokwe, Mechanisms of cellular injury in African trypanosomiasis, Veterinary Bulletin 64(7): (March 1994), 611-620, ISSN 1684-5315.

[12] F.W.Jennings, The anaemia of parasitic infections, Proceedings of the $7^{\text {th }}$ International Conference of the World Association for the Advancement of Veterinary Parasitology, pp. 41-67, ISBN 0-12655 365- 3, Thessalonica, Greece, October 15-19, 1975.

[13] I.O.Igbokwe, C.O.Nwosu, Lack of correlation of anaemia with splenomegaly and hepatomegaly in Trypanosoma brucei and Trypanosoma congolense infections of rats. J Comp Pathol 1997;117:261-5

[14] M.A.Akanji, O.S. Adeyemi, S.O.Oguntoye, F. Sulyman, Psidium guajava extract reduces Trypanosomiasis associated lipid per-oxidation and raises glutathione concentra-tions in infected animals. EXCLI J 2009; 8:148-54.

[15] Abeer A. Abd El-Baky, Shaymaa I. Salem. Clinico pathological and Cytological Studies on Naturally Infected Camels and Experimentally Infected Rats with Trypanosoma evansi. World Applied Sciences Journal 14 (1): 42-50, 2011.

[16] Z.I.Chaudhary, J. Iqbal, Incidence, biochemical and haematological alterations induced by natural Trypanosomiasis in racing dromedary camels. Acta Trop, 2000, 77, 209-213

[17] V.O.Anosa, L.L. Logan - Henfrey, C.W. Wells, The haematology of T. congolense infection in cattle 11: Macrophages structure and function in adult Boran cattle. Comparative Haematology International, 1997a, 7:23 - 29.

[18] A.Abubakar, B.Iliyasu, A.B.Yusuf, A.C. Igweh, N.A.Onyekwelu, B.A.Shamaki, D.O.Afolayan, E.O.Ogbadoyi, Antitrypano-somal and haematological effects of selected Nigerian medicinal plants in Wistar rats. Biokemistri 2005; 17:95-9.

[19] J.T.Ekanem, O.M. Kolawole, O.C. Abbah, Trypanocidal potential of methanolic ex- tract of Bridelia ferruginea benth bark in Rattus novergicus. Afr J Biochem Res 2008; 2:45-50.

[20] F.A.Sulaiman, O.S. Adeyemi, Changes in haematological indices and protein concentrations in Trypanosoma brucei infected rats treated with homidium chloride and diminazene aceturate. EXCLI Journal, 2010, 9: 39-45. 